\title{
Reconstruction of Partial Thickness Post Traumatic Lip Defect With Modified Webster Flap: A Case Report
}

Vidya Devi V¹, Pavan Kumar B², Madhusudhana Rao G³

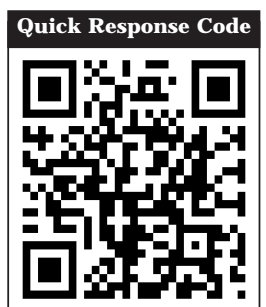

doi: $10.5866 / 2017.9 .10116$

${ }^{1}$ Senior Lecturer

${ }^{2}$ Prof \& HOD

${ }^{3}$ Reader

Department of Oral and Maxillofacial Surgery

Kamineni Institute of Dental Sciences

Narketpally, Nalgonda

\section{Article Info:}

Received: April 11, 2017

Review Completed: May 13, 2017

Accepted: J une 12, 2017

Available Online: J une, 2017 (www.nacd.in)

(c) NAD, 2017 - All rights reserved

\section{Email for correspondence:}

vidya.devi.vuyyuru@gmail.com

\begin{abstract}
:
Soft tissue trauma, especially with tissue loss, requires reconstruction methods that providetensionless closure without compromising on the esthetics. Over the years a vast number of local flaps have been described for reconstruction of the upper lip. We describea casereport of management of traumatic tissue loss involving the upper lip with a modification of Webster flap.
\end{abstract}

Key words: Soft tissue injury, U pper Lip reconstruction, Local flap

\section{Introduction:}

Soft tissue trauma resulting in tissue loss poses a challenge, more so when such loss involves the face and vital aesthetic units such as the lips. The concern here is twofold. There is an immediate need to reconstruct the defect and achieve primary closure, but care must betaken that the esthetics of the adjacent region are not sacrificed while achieving this. It has been a long held wisdom to place incisions and raise flaps such that these incisions fall intothe natural folds of theskin. Based on these principles Webster had proposed an advancement flap for management of midline defects and scar revision which we have used for correction of a post traumatic, partial thickness midline defect of the upper lip. ${ }^{1}$

\section{Case Report:}

A 26 year old male reported to the casualty with soft tissue injuries to the face including tissue loss to the upper lip, intraoral laceration and lower vestibular degloving injury. Theintraoral laceration and the degloving injuries were treated by primary closure under local anesthesia and upper lip defect closure was planned under general anesthesia. 
The injury to the upper lip extended $7 \mathrm{~mm}$ to the right of the midline and $5 \mathrm{~mm}$ to the left of the midline, from the wet/dry line of the lip crossing the vermilion border of the lip and extending till the collumella. Both the cupid's bow and the philtral columns were lost. The defect was approximately 3 $\mathrm{mm}$ in thickness involving the superficial orbicularis ori muscles. A $4 \mathrm{~mm}$ laceration extended into the labial mucosa without any tissue loss (Figure 1).

The patient was treated under general anesthesia. Standard sterilization protocol was followed. Markings were placed for the crescent shaped alar incisions, according to the Webster flap, extending al ong the base of the nose and joining the edges of the defect. Nasolabial releasing incisions were marked. The alar incisions and the nasolabial incisions were separated by $5 \mathrm{~mm}$ of intact skin (Figure 2). After infiltration of local anesthetic solution, incisions were placed along the markings.

The skin was dissected from the underlying muscle layer on both sides of the defect extending up to the alar incisions. The labial muscle was dissected from the underlying mucosa (Figure 3). The released musclelayer was then extended across the midline and sutured and the mucosal laceration was cl osed with interrupted sutures with 4-0 vycril. The skin was undermined from the nasolabial incisions and the skin flap was advanced and closed without tension, with 5-0 prolene vertical mattress sutures (Figure 4). Due to the greater availability of the skin on the left side as compared to the right side, the closure was achieved $2 \mathrm{~mm}$ right of the midline. Theskin of the lateral side of the nasolabial incisions was then undermined and the secondary defect was closed with primary closure with 5-0 prolene. Suture removal was done after 1 week. Follow up was done for a month (Figure 5). Further follow-up is planned for assessment of long term results.

\section{Discussion}

Lip defects can occur due to a large variety of reasons ranging from congenital defects like clefts, excision of lesions, to traumatic defects resulting in tissue loss and scaring. Regarding the size of the defect it has been given that defects involving onethird of the lower lip or one-quarter of the upper lip can be satisfactorily treated by wedge excision and direct suture. Defects between one-third and twothirds of the lip length require a lip switch or local advancement flap. When the lip defect is greater than two-thirds, local flaps or distant tissue is necessary for reconstruction. ${ }^{2}$ The anatomy of thelip, in that it is a structure with one free margin, makes it prone to distortion particularly when primary closure is attempted. As such this remains an ideal option only for smaller defects. Primary closure in larger defects, even when possible, may al so produce tightness over thelip, difference in protrusion of the upper and lower lip and sometimes even change in the position of the commissure. ${ }^{1}$ Thus flaps provide a better alternate for the larger defects. Treatment plan is also guided by the thickness of the defect and the involvement of the underlying muscles.

Over time, a large number of flaps... and techniques have been proposed for the management of larger midline defects and the reconstruction of the upper lip. The Roman, Aulus Cornelius Celsus, first described the use of bilateral buccal flap, made between horizontal parallel incisions with the pedicle based laterally, for upper lip reconstruction in the first century AD. Lisfranc in 1883 and Von Burn's in 1889 further reported this method. This flap resulted in tightness across the flap and loose excessive tissue above and bel ow the flap, a problem dealt by Burrow by excising triangular pieces of tissue at the corners of the flap above and bel ow the incision. ${ }^{1}$ Modifications of these methods were designed by Fries in 1973 and Meyer and Shapiro in $1973 .^{2}$

Advancement flaps with curved peri-alar incision was first described by Diffenbach in 1845 to enable the bilateral cheek flaps to be drawn together. He described this method specifically for the defects with shortening of thelip wheretheteeth and the maxilla are exposed till the base of the nose. Stone in 1908 modified this flap to remove a crescent shaped tissue from adjacent to the ala to allow for the advancement of the flap. Lindeman described the use of alar incision without excision of thetissue, using perinasal cheek flaps for closure of cleft lip.

Flaps with pedicles based superiorly were described by Malgaigne and Sedillot (1889), Ferris smith (1942) and Paleta (1954). Inferiorly based flaps for lip repair have been described by, Denonvillers (1919), Blasius(1919), and Nelaton and Ombredanne (1919). Local rotation flap and cheek rotation flap have also been described. ${ }^{3}$ The V-Y advancement flap, also known as the island pedicle flap, with bilateral, opposed design, has been advocated for reconstruction of full and partial 


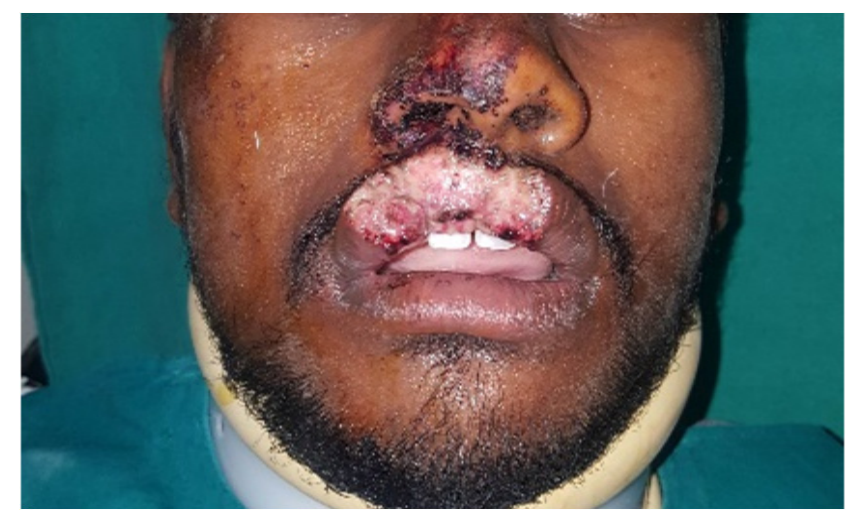

Figure 1: Post traumatic soft tissue defect showing tissue loss to the upper lip, intraoral laceration and lower vestibular degloving injury

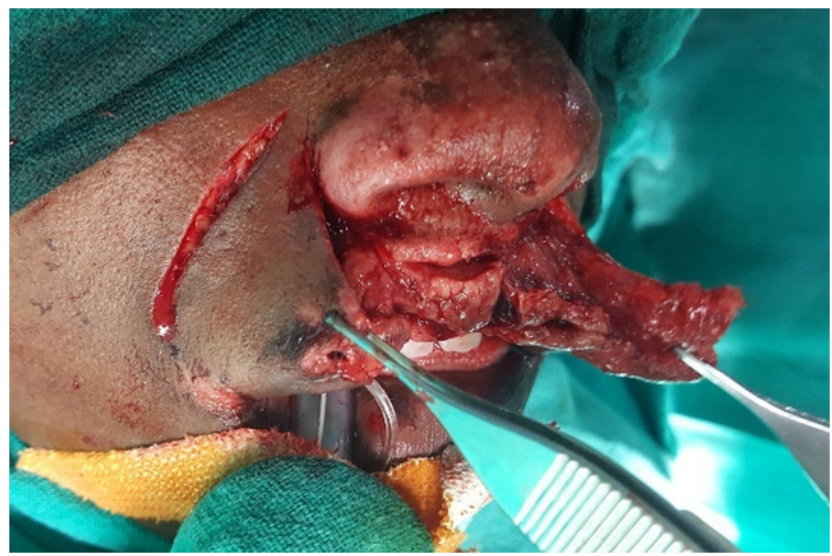

Figure 3: Elevation of Flap

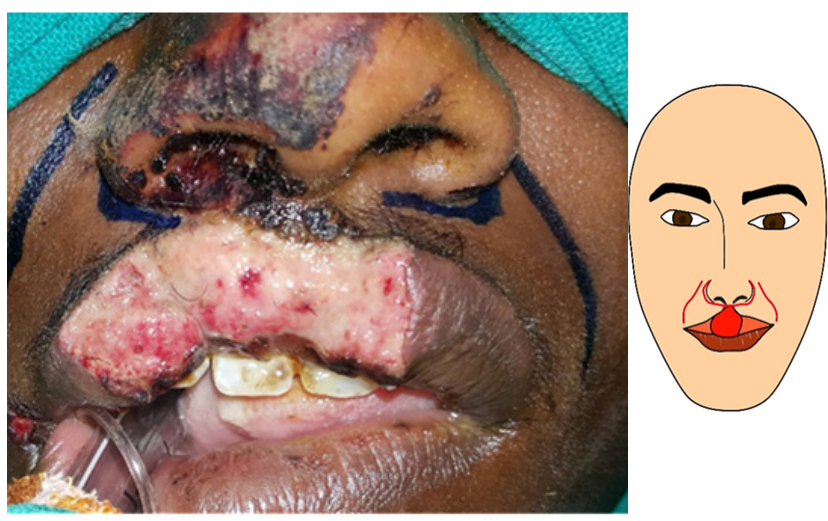

Figure 2: Clinical picture showing markings for advancement flap

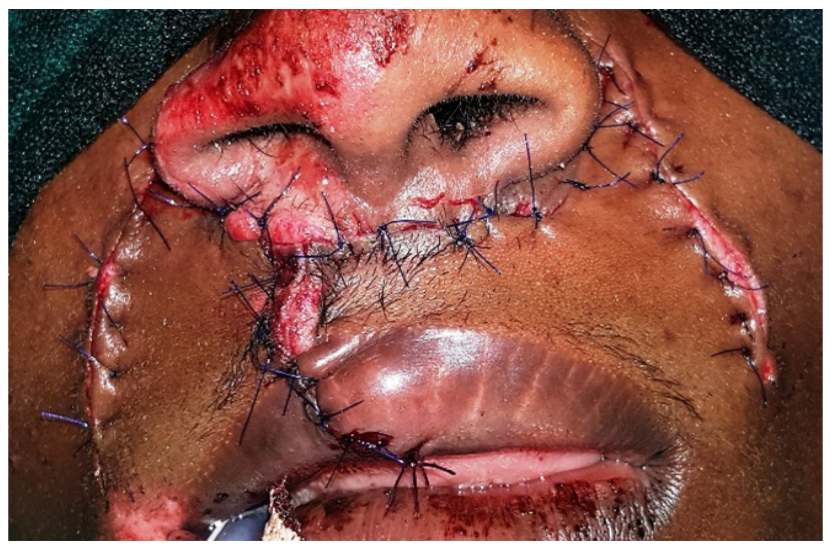

Figure 4: Clinical picture showing closure with 5-0 prolene vertical mattress sutures

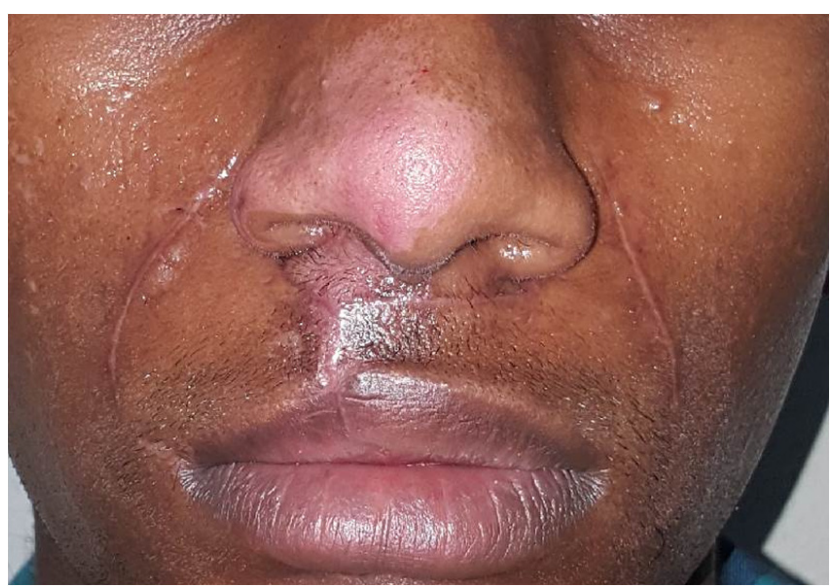

Figure 5: Post operative clinical picture showing complete healing at 4 weeks. 
thickness lip defects. ${ }^{4} U$ se of the opposite lip tissue to repair defects has been advocated by Sabattini of I mola (1837), Gordon Buck (1908) and Eastlander. Abbe, in 1898, reported a flap from the middle of the lower lip to fill upper lip defects, which has since then been one of the most frequently used methods. Distal flaps from the temporal, frontal and other regions have also been described. ${ }^{1}$

Reconstruction of the cupid's bow in particular has been achieved by rhombic transposition flaps as described by Bickle and Bennett or a modified mucosal advancement flap designed by M ellette and Mellette, or a 2 vermilion advancement flaps and a rotational hemiphiltrum skin flap described by Valentiet al. ${ }^{5}$

Webster first described his crescentic perialar cheek extension flap in 1954 based on Diffenbach's method, with variations for management different of partial and full thickness defects. ${ }^{1,6}$ In the present case, we used a modification of the Webster flap with additional nasolabial release incisions to reduce the tension across the advancement flap and increase the length of tissue available. This was especially needed on the left side as thetissue loss was present more to the right. The alar and the paranasal incisions remained separate. The flap produced was an inferiorly based flap, paranasal cheek flap, though a bridge of tissue remained connecting the flap superiorly. The resultant closure was found to be without tension, and the scars of the release incision were well hidden in the alar and nasolabial folds.

\section{Conclusion}

Even though lip defects of less than $1 / 3^{\text {rd }}$ the width are said to be eligible for primary closure, this closure may lead to various distortions. As such the modified Webster flap provides for an ideal option for tension free and esthetic closure of partial thickness midline defects even when they are less than a third of the lip width.

\section{References}

1. Gullane PJ, Havas TE. Lip reconstruction. Facial plastic surgery 1987; 4(3):233-45.

2. Webster J P. Crescentic peri-alar cheek excision for upper lip flap advancement with a short history of upper lip repair. Plastic Reconstructive Surg 1955; 16(6):434-64.

3. Weerda H. Reconstructive facial plastic surgery: a problemsolving manual. Univ of California Press; 2001.

4. Kaufman AJ, Grekin RC. Repair of central upper lip (philtral) surgical defects with island pedicleflaps. Dermatol Surg 1996; 22:1003-7

5. Gatnau J R, Ruiz-Salas V, Fernández MA, Puig L. Reconstruction for Defects at the Base of the Philtrum Affecting the Upper Lip Vermilion. Dermatol Surg 2016; 42(5):677-80.

6. Wang SQ, Behroozan DS, Goldberg LH. Perialar crescentic advancement flap for upper cutaneous lip defects. Dermatol Surg 2005; 31(11):1445-7.

\section{Gain quick access to our journal online View our journal at www.nacd.in}

